\title{
Analysis of the Near-road Fine Particulate Exposure to Pedestrians at Varying Heights
}

\section{Aerosol and Air Quality Research}

\author{
Satya S. Patra ${ }^{1}$, Lelitha Devi Vanajakshi ${ }^{2 *}$ \\ ${ }^{1}$ Lyles School of Civil Engineering, Purdue University, West Lafayette 47906, USA \\ ${ }^{2}$ Department of Civil Engineering, IIT Madras, Chennai 600036, India
}

\section{OPEN ACCESS}

Received: May 9, 2021

Revised: September 13, 2021

Accepted: September 16, 2021

${ }^{*}$ Corresponding Author:

lelitha@civil.iitm.ac.in

\section{Publisher:}

Taiwan Association for Aerosol Research

ISSN: $1680-8584$ print

ISSN: 2071-1409 online

\section{Copyright: The Author(s).} This is an open access article distributed under the terms of the Creative Commons Attribution License (CC BY 4.0), which permits unrestricted use, distribution, and reproduction in any medium, provided the original author and source are cited.

\section{ABSTRACT}

Scientific literature has overlooked how $\mathrm{PM}_{2.5}$ concentrations vary with varying pedestrian heights near a roadway. Understanding this is important because walking is an essential commuting element of a sustainable transportation system, and pedestrians' height varies widely. Therefore, the focus of the current study is to bridge this gap using results from CALINE 4 model and mobile $\mathrm{PM}_{2.5}$ measurements. In CALINE 4, a simple pedestrian pathway depicting the selected study site located near the Sardar Patel Road, Chennai, India, was simulated. The $\mathrm{PM}_{2.5}$ concentrations were estimated on this pathway at varying heights $(0.1-1.8 \mathrm{~m})$ in 135 simulated runs. Subsequently, the sensitivity of the $\mathrm{PM}_{2.5}$ exposure difference across heights was explored with varying ambient $\mathrm{PM}_{2.5}$ concentrations, wind speed, traffic volume, and traffic compositions. Results indicated that the $\mathrm{PM}_{2.5}$ concentrations reduced with increasing heights of pedestrians in all the modelled runs. When this $\mathrm{PM}_{2.5}$ exposure difference was investigated with varying surrounding conditions, it was found that the difference in $\mathrm{PM}_{2.5}$ exposure across heights was influenced by the wind speed, traffic volume, and traffic composition. Ambient $\mathrm{PM}_{2.5}$ concentrations had no discernible effect on it. Car-dominated traffic with a higher mode share of heavy commercial vehicles was marked with the highest $\mathrm{PM}_{2.5}$ exposure difference across heights. For traffic volume, it was observed that for every 100 vehicles $\mathrm{hr}^{-1}$ increase in traffic volume, the $\mathrm{PM}_{2.5}$ exposure difference increased by $0.13 \mu \mathrm{g} \mathrm{m}^{-3} \mathrm{~m}^{-1}$ in the range of pedestrian's height. For wind speed, calculations suggested that for every $1 \mathrm{~m} \mathrm{~s}^{-1}$ increase in wind speed, the $\mathrm{PM}_{2.5}$ exposure difference was reduced by $0.095 \mu \mathrm{g} \mathrm{m}^{-3} \mathrm{~m}^{-1}$ in the range of pedestrian's height. Finally, to bolster the modelling results, mobile $\mathrm{PM}_{2.5}$ measurements (using portable, low-cost optical particle sensors) were conducted near a busy urban roadway at two different heights, $80 \mathrm{~cm}$ and $150 \mathrm{~cm}$, during peak and off-peak hours. The results of mobile measurements were found to be consistent with CALINE 4 modelled results.

Keywords: $\mathrm{PM}_{2.5}$, CALINE 4, Pedestrian exposure, Exposure gradient

\section{INTRODUCTION}

Ambient air pollution is a significant environmental problem threatening several lives. Epidemiological studies have provided substantial evidence relating routine ambient air pollution exposure to adverse health outcomes (Atkinson et al., 2016; Nawahda et al., 2012; Patra et al., 2021c). Overall, one out of ten deaths worldwide could be attributed to air pollution (Guilbert et al., 2019). World Health Organization (WHO) estimates that about $91 \%$ of the world's population resides in areas where air quality exceeds the prescribed limits (WHO, 2021). Road traffic is one of the primary sources contributing to this deteriorated air quality in urban areas (Carvalho et al., 2018; Hassanpour Matikolaei et al., 2019; Kanok and Waheed, 2006; Matz et al., 2019). Trafficrelated air pollution is a unique combination of particles and gaseous compounds that can come directly from tailpipe exhaust, tire and brake wear, road dust re-suspension, and secondary aerosols (Amouei Torkmahalleh et al., 2020). Concerns about traffic-related air pollution are higher because emissions occur at lower heights, contributing to surface pollution (Guilbert et al., 2019). Amongst 
the major traffic-related pollutants, Particulate Matter (PM) is identified as a major component, which is the leading cause of infant mortality and affects more people than any other pollutants (Wang et al., 2020). Commuters close to traffic face elevated levels of fine particulate $\left(\mathrm{PM}_{2.5}\right.$; particulate matter having a size less than $2.5 \mu \mathrm{m}$ ) concentrations (Kumar and Goel, 2016). The situation is worsening as the vehicle population increases worldwide, along with an increase in vehicle kilometres travelled and traffic congestion. Therefore, it has become the need of the hour to understand and characterize the traffic-related PM concentrations at different commuting conditions.

Walking is an essential commuting element of a sustainable transportation system, which reduces dependency on motorized vehicles, fosters community living, and enhances the local economy (Luo et al., 2018). It also helps maintain individual fitness and improves public health (Laverty et al., 2013). However, with the increasing number of motorized traffic on roads, pedestrians are forced to walk by streets with heavy traffic and are exposed to elevated fine particulate levels. Consequently, several researchers have attempted to understand the factors influencing pedestrians' exposure to $\mathrm{PM}_{2.5}$. In Delhi, India, a study reported that the measured on-road $\mathrm{PM}_{2.5}$ concentrations exceeded the ambient $\mathrm{PM}_{2.5}$ levels by an average of $40 \%$ (Goel et al., 2015). Recent research in Singapore has shown that pedestrian particle exposure is the worst among other commuting modes (Tan et al., 2017).

Literature suggests pedestrian routes marked with heavy traffic congestion, bus stops, or traffic intersections are associated with higher levels of $\mathrm{PM}_{2.5}$ (Boarnet et al., 2011; Goel and Kumar, 2015; Greaves et al., 2008; Qiu and Li, 2015; Schneider et al., 2015; SM et al., 2019). Qui and $\mathrm{Li}$ (2015) indicated that $\mathrm{PM}_{2.5}$ exposure to pedestrians is also influenced by the intersection design. Another study reported that both underpass and overpass intersections reduce pedestrians' $\mathrm{PM}_{2.5}$ exposure significantly (Qiu and Peng, 2015). In addition, researchers have indicated that the hour of commuting also influences the $\mathrm{PM}_{2.5}$ pedestrian exposure. For example, Quiros et al. (2013) reported that $\mathrm{PM}_{2.5}$ exposure for pedestrians during evening hours is less than morning and afternoon hours. Besides, apart from surrounding conditions and the time of the day, meteorological variables such as wind speed and wind direction are also reported to affect the PM exposure levels. In general, as wind speed increases, dispersion occurs both vertically and along the wind direction, influencing PM concentrations both horizontally and vertically (Conte et al., 2018; Holmes et al., 2005; Molnár et al., 2002).

While several studies on pedestrians' exposure to fine particulates have been published, most of them focus on understanding the variation of $\mathrm{PM}_{2.5}$ levels with commuting conditions, traffic volume, and meteorology. However, a key aspect, i.e., the variability of $\mathrm{PM}_{2.5}$ exposure for different pedestrian heights, has been overlooked. Naively one may expect that pedestrians with shorter height are exposed to higher pollutant concentrations than the tall pedestrians while walking along a busy roadway, on account of their breathing zone being closer to the vehicle exhausts. Studies have been reported in the literature that suggests a significantly lower concentration of pollutants at higher floors relative to ground floors (Goel and Kumar, 2016). However, similar evaluation for different pedestrian heights has received little critical attention in the scientific literature. It is crucial to consider this aspect because the heights vary widely between children and adults. Knowing the vertical gradient of $\mathrm{PM}_{2.5}$ exposure across this range can provide valuable insights into potential health risks. Certain limited literature suggests that the concentration of particles and carbon monoxide is greater at a child's height than at an adult's height near roadways (Kaur et al., 2007; Wang et al., 2021). However, the factors influencing this concentration difference have not been investigated. Therefore, the current study aims to understand how $\mathrm{PM}_{2.5}$ exposure varies with different pedestrian heights near urban roadways, and explores how this exposure difference varies with varying traffic volume, wind speed, traffic composition, and ambient $\mathrm{PM}_{2.5}$ concentration. For the same, a Gaussian plume line source model, CALINE 4 (Benson, 1988; Fung et al., 2013), is used. Finally, mobile $\mathrm{PM}_{2.5}$ measurements were conducted near a busy arterial in Chennai, India, to experimentally verify the simulation results.

Numerous methods are available to measure particle mass concentrations. The U.S. Environmental Protection Agency (U.S. EPA) has set the gravimetric filter method as a reference to measure $\mathrm{PM}_{2.5}$ levels (U.S. EPA, 1997). These methods are accurate and precise but are not capable of providing temporal information (Sousan et al., 2016a). Another method, namely Cascade impactors, utilize a combination of the gravimetric method and chemical analysis to determine particle mass 
(Hinds, 1999). Microscopy is another highly accurate method for determining particle mass concentration. However, all these methods are labor-intensive, time-consuming, and expensive. Another set of instruments exist that calculate the particle mass indirectly by estimating the particle number concentration. Examples of such instruments are scanning mobility particle sizer (SMPS) and aerodynamic particle sizer (APS) (Sousan et al., 2016a). These instruments make appropriate assumptions about particle density to measure the mass concentration. While these methods are fast and automatic, their expensive nature makes them impractical for personal exposure evaluations. For the same, optical particle counters are used. Optical instruments measure the intensity of light scattered by aerosol particles, which is used to estimate the particle mass concentrations (Hinds, 1999). Mobile PM measurements using optical particle counters are quite feasible due to their low-cost and portable nature, making it easy to collect data by carrying it during the daily commute.

Consequently, the use of low-cost sensors for urban surveillance and personal exposure studies in the scientific community has been growing recently. For instance, low-cost PM sensors have been used in various environments such as residential and occupational environments (Krause et al., 2019; Merico et al., 2019; Moreno-Rangel et al., 2018; Omidvarborna et al., 2021; Patra et al., 2021c), traffic environments (Chen et al., 2019; Forehead et al., 2020), and urban hotspots (Feenstra et al., 2019; Lim et al., 2019; Magi et al., 2019; SM et al., 2019). The networkwide implementation of low-cost sensors to obtain high spatio-temporal resolution data on $\mathrm{PM}_{2.5}$ has also gained popularity (Bi et al., 2020; Datta et al., 2020; Gao et al., 2015; Zikova et al., 2017).

The current study uses two low-cost optical PM 2.5 sensors (Models: Sensiron SPS30 and Panasonic $\mathrm{PM}_{2.5}$ ) for outdoor mobile $\mathrm{PM}_{2.5}$ measurements, which need elaborate calibration to have high accuracy. Due to the lack of availability of two portable low-cost $\mathrm{PM}_{2.5}$ sensor units from the same manufacturer during the study, the measurements were conducted using two different low-cost $\mathrm{PM}_{2.5}$ sensors, which are similar in performance. The selected sensors use the same measurement techniques and have identical detection limits. Additionally, to ensure agreement, numerous co-location tests were performed between the sensors and also with a laboratory-grade particle counter. However, in this study, the outdoor co-location was done for only a limited period. Because of this, the study makes no attempt to comment on any quantitative estimation of $\mathrm{PM}_{2.5}$ differences between pedestrians of varying heights. It only compares the values to understand the relative impact. Overall, the study presents a novel examination of $\mathrm{PM}_{2.5}$ concentration variation across the height of pedestrians that has been overlooked in the pedestrians' pollutant concertation evaluation literature.

\section{METHODS}

The approach and execution adopted in this study can be grouped into two categories. They are CALINE 4 Simulation and mobile measurements. The following sections outline the research methodologies for both these categories.

\subsection{CALINE 4 Simulations}

The current study aims to understand how $\mathrm{PM}_{2.5}$ concentration changes with changing pedestrian heights near roadways. For the same, the California Line Source Dispersion Model (CALINE 4) is used. CALINE 4 is the most widely used vehicular pollutant dispersion model (Dhyani et al., 2013). It is a line-source air quality model developed by the California Department of Transportation. It employs the Gaussian diffusion equation and the mixing zone concept to model traffic pollutant dispersion (Benson, 1984). The model discretizes a roadway link into series of finite segments, then estimates the pollutant concentration in each segment, and finally adds up those estimates to determine the pollutant concentration for a specific receptor position (Majumdar et al., 2008). The concentration at a receptor point $(x, y, z)$ is calculated using Eq. (1) (Chen et al., 2009).

$$
C(x, y, z)=\frac{q}{2 \pi \sigma_{y} \sigma_{z}}\left\{e^{\frac{-(z-H)^{2}}{2 \sigma_{z}^{2}}}+e^{\frac{-(z+H)^{2}}{2 \sigma_{z}^{2}}+}\right\} \int_{y_{2}}^{y_{1}} e^{\frac{-y^{2}}{2 \sigma_{y}^{2}}} d y
$$


where, $C$ is the concentration of pollutant; $q$ is the line source's length; $\sigma_{y}$ and $\sigma_{z}$ are the horizontal and vertical Gaussian dispersion parameters; $H$ is the source height; and $y_{1}$ and $y_{2}$ are the endpoints of the divided finite line sources.

Evaluation studies have been performed assessing how well the CALINE 4 simulated pollutant concentrations match the real-world emissions. Agharkar (2017) compared the $\mathrm{PM}_{2.5}$ concentrations forecasted by CALINE 4 in the City of Cincinnati and reported good agreement $(p=0.9482$ ) with the measured on-site data. Goud et al. (2015) evaluated the performance of CALINE 4 to estimate the $\mathrm{PM}_{2.5}$ concentration at a traffic intersection in Bangalore, India and reported the performance to be valid and acceptable. Prakash et al. (2016) predicted the $\mathrm{PM}_{10}$ concentrations along a highway in Mysuru, India, and reported the predicted concentrations to be comparable with the monitored values $\left(R^{2}=0.943\right)$. Besides good modelling functionality, CALINE 4 offers several advantages over other pollutant dispersion models, such as the need for lesser input data, smooth user interface, and ability to reliably predict air quality up to $500 \mathrm{~m}$ (Dhyani et al., 2013; Dhyani and Sharma, 2017; Majumdar et al., 2010). The abovementioned advantages motivated the use of CALINE 4 in the current study to explore the vertical difference in $\mathrm{PM}_{2.5}$ concentrations near roadways in the range of pedestrian height. However, a major limitation of the CALINE 4 model is that the Gaussian dispersion model does not incorporate the recent developments in turbulence theory (Batterman et al., 2010). Also, CALINE 4 does not model the non-exhaust portion of traffic-related particle emissions (Chen et al., 2009).

\subsubsection{Model formulation}

A simple 3-lane link geometry (shown in Fig. 1) was used as an input in the CALINE 4 model. Nineteen receptors (points where $\mathrm{PM}_{2.5}$ concentrations were calculated as the output of the model) were placed at a lateral distance of $6 \mathrm{~m}$ from the drawn link, each separated by a distance of $10 \mathrm{~cm}$ in the vertical direction. Overall, the $\mathrm{PM}_{2.5}$ concentrations up to a height of $180 \mathrm{~cm}$ were analyzed.

Different input conditions were used to run the CALINE 4 model. This was done to understand the sensitivity of the vertical differences in $\mathrm{PM}_{2.5}$ across the receptor points with changing surrounding conditions. For the same, three regimes (Low, Medium, and High) of wind speed and ambient PM 2.5 concentrations were considered in the analysis. Similarly, three regimes for traffic volumes were also considered. The values corresponding to each regime for these variables are summarized in Table 1. These values were chosen because the average $\mathrm{PM}_{2.5}$ concentration of Chennai is $33 \mu \mathrm{g} \mathrm{m}^{-3}$ (Chen et al., 2020); the traffic volume in the stretch during peak hour is around 2300 vehicles $\mathrm{h}^{-1}$ (Sampathkumar et al., 2018); and, the wind speed referring to Beaufort scale of light and gentle breeze in low wind speed category, moderate breeze in medium wind speed category, and Fresh and strong breeze in high wind speed category (Salvacao et al., 2015). In addition to these input parameters, the effect of traffic composition on the vertical differences in $\mathrm{PM}_{2.5}$ was also explored. To do so, five categories of traffic compositions were included. They were, Category I (Car-60\%, 2-Wheeler (2W)-20\%, Light Commercial Vehicles (LCV)-10\%, and Heavy Commercial Vehicles (HCV)-10\%), Category II (Car-20\%, 2W -60\%, LCV-10\% and HCV-10\%), Category III (Car-40\%, 2W40\%, LCV-10\% and HCV-10\%), Category IV (Car-60\%, 2W-20\%, LCV-5\% and HCV-15\%), and Category V (Car-20\%, 2W-60\%, LCV-5\% and HCV-15\%). The emission factors of $\mathrm{PM}_{2.5}$ for each vehicle type were taken from the Automotive Research Association of India (ARAI, 2007).

For each CALINE 4 model run, one regime from each input variable (listed in Table 1) was chosen along with a vehicle composition category. For instance-medium ambient $\mathrm{PM}_{2.5}$ concentrations with low wind speeds and high traffic volume with Category III composition. Therefore, considering all the permutations, a total of 135 simulated runs were performed, and the concentrations of $\mathrm{PM}_{2.5}$ at receptors in each run were recorded. These concentrations were reported as an hourly average concentration by the model. Finally, exploratory analysis using comparison plots was performed to examine the near-roadway vertical differences in $\mathrm{PM}_{2.5}$ concentrations up to $180 \mathrm{~cm}$ height, and to see how these differences changed with changing ambient $\mathrm{PM}_{2.5}$ concentration, wind speed, traffic volume, and traffic composition.

To understand the sensitivity of vertical differences in $\mathrm{PM}_{2.5}$ concentrations with respect to individual parameters (vehicle volume, traffic composition, wind speed, and ambient $\mathrm{PM}_{2.5}$ concentrations), a gradient variable (G) as shown in Eq. (2) is introduced and calculated for each 
a)

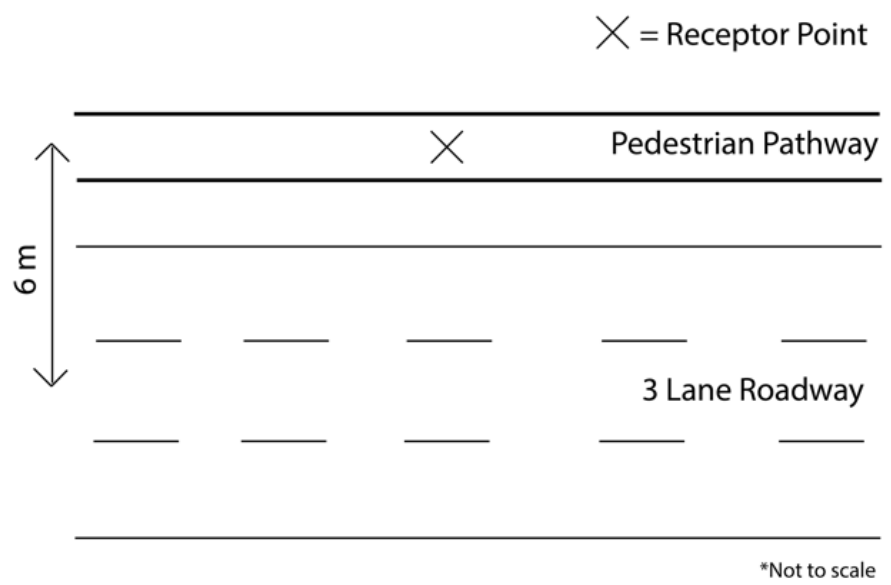

b)

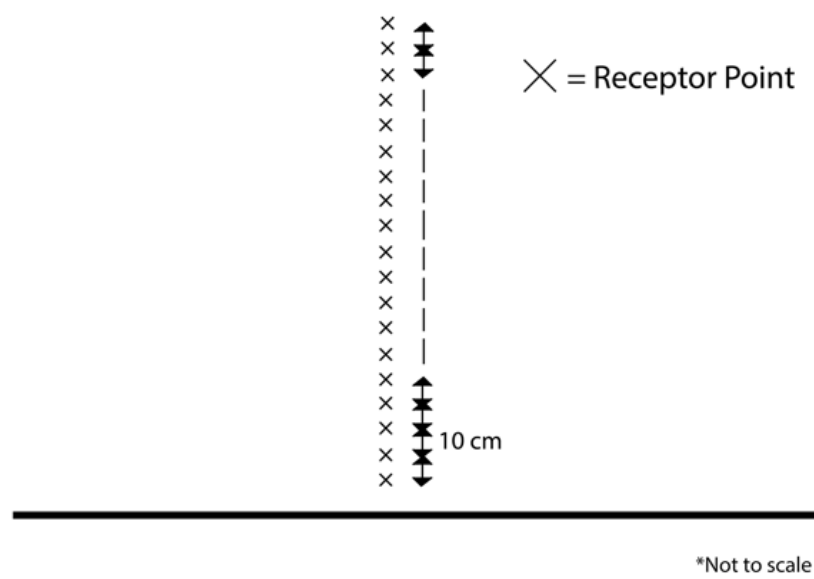

Fig. 1. (a) Top View, (b) Side View of the link geometry used in the CALINE 4 model.

Table 1. CALINE 4 input values in different regimes as considered in the study.

\begin{tabular}{llll}
\hline \multirow{2}{*}{ Input Variables } & \multicolumn{2}{c}{ Values } \\
\cline { 2 - 4 } & Low & Medium & High \\
\hline Ambient $\mathrm{PM}_{2.5}$ & $20 \mu \mathrm{g} \mathrm{m}^{-3}$ & $40 \mu \mathrm{g} \mathrm{m}^{-3}$ & $60 \mathrm{~m}^{-3}$ \\
Wind Speed & $3 \mathrm{~m} \mathrm{~s}^{-1}$ & $7 \mathrm{~m} \mathrm{~s}^{-1}$ & $10 \mathrm{~m} \mathrm{~s}^{-1}$ \\
Traffic Volume & 1000 vehicles $\mathrm{hr}^{-1}$ & 2000 vehicles hr & 3000 vehicles hr $^{-1}$ \\
\hline
\end{tabular}

simulation. This value is introduced because the absolute numerical value of $G$ indicates the steepness of $\mathrm{PM}_{2.5}$ concentration across height, i.e., if the absolute numerical value of $\mathrm{G}$ is higher, the difference in $\mathrm{PM}_{2.5}$ concentration between lower and higher heights is more.

$G=\frac{\left(\mathrm{PM}_{2.5}\right)_{a}-\left(\mathrm{PM}_{2.5}\right)_{b}}{a-b}$

Here, $a$ and $b$ are the upper and lower limits of receptor points in the CALINE 4 model, which are $1.8 \mathrm{~m}$ and $0.1 \mathrm{~m}$, respectively. $\left(\mathrm{PM}_{2.5}\right)_{\mathrm{x}}$ represents the $\mathrm{PM}_{2.5}$ concentration at the receptor at $\mathrm{x} \mathrm{m}$ height. To understand the effect of each individual variable on the difference in $\mathrm{PM}_{2.5}$ concentration across height, $G$ was calculated for different simulations where the value of the variable of interest (for instance: traffic volume) was increased sequentially while keeping the values of other variables constant. Subsequently, the $G$ was calculated for each changing value of the variable of interest and analyzed. 


\subsection{Mobile Measurements}

Along with the simulated results, as discussed before, mobile $\mathrm{PM}_{2.5}$ measurements were also performed near an urban roadway at different heights to bolster the findings. This section discusses the materials and methodology adopted for mobile measurements.

\subsubsection{Instruments}

Two portable, low-cost particle sensors were used for mobile measurements in this study; they were Sensiron SPS30 and Panasonic PM 2.5 sensor. Sensiron SPS30 is a low-cost optical PM 2.5 sensor with dimensions $\sim 41 \mathrm{~mm} \times 41 \mathrm{~mm} \times 12 \mathrm{~mm}$ (Sensiron, 2018). This portable, low-cost optical $\mathrm{PM}_{2.5}$ sensor can measure mass concentrations in the $1-1000 \mu \mathrm{g} \mathrm{m}^{-3}$ range. SPS30 samples air with a small integrated fan, with a minimum sampling interval of one second. The counting efficiency of the SPS30 comes pre-calibrated with potassium chloride salt particles and TSI DustTrakTM DRX Aerosol Monitor 8533 as a reference (Sensiron, 2018). To interface and download the collected data from SPS30, a Raspberry Pi 4 single-board microprocessor was used. A custom python program built on top of an open-source python library - Raspi Driver SPS30 developed by UnraveITEC (UnravelTEC, 2019) was written to read, write, and store the output of the SPS30 on the local memory of Raspberry Pi 4. The other $\mathrm{PM}_{2.5}$ sensor, Panasonic $\mathrm{PM}_{2.5}$ (Nakayama et al., 2018), has nearly similar specifications as the SPS30 sensor. This sensor was developed at Panasonic labs in Japan and was recently calibrated for Indian conditions. The Panasonic PM 2.5 sensor came with a mobile application to log the sensor's output. The sampling interval for both the sensors was set to be 1 minute.

To evaluate the performance of both of the low-cost PM sensors, they were co-located against each other, and also with respect to a lab-grade portable aerosol spectrometer, PAS 1.109, manufactured by the GRIMM (GRIMM, 2010). GRIMM PAS 1.109 is a state-of-the-art optical particle counter that measures particle number concentrations in 32 bins. It employs a laser at $0.5 \mathrm{~mW}$ to detect large particles and $30 \mathrm{~mW}$ to detect small particles. The $\mathrm{PM}_{2.5}$ output of the GRIMM instrument was recently calibrated before the data collection campaign. The performance of the GRIMM PAS has been previously assessed in the literature (Crilley et al., 2018; Dinoi et al., 2017). All the co-location experiments in this study were performed in both indoor and outdoor conditions and are further discussed in the next subsection. Statistical tests were performed to quantify the assessment.

\subsubsection{Sensor co-location}

This study conducted three kinds of sensor co-location experiments. Firstly, both the SPS30 and Panasonic PM 2.5 sensors were co-located against the GRIMM PAS 1.109 in indoor and outdoor conditions. The location selected for indoor experiments was a well-ventilated air-conditioned room - ITS laboratory, IIT Madras, which has moderate activity levels throughout the working hours (9 AM-6 PM) in a day. The outdoor co-location was performed on a pedestrian pathway located near the Sardar Patel Road, Chennai, India (the characteristic of location is discussed in the following sub-section). The aim of these co-locations was to assess the performance of the low-cost sensors relative to a state-of-the-art PM reference instrument.

Secondly, the SPS30 and Panasonic PM 2.5 sensors were co-located against each other. This colocation was meant to check the agreeability of low-cost sensors' outputs under identical conditions. These intra-sensor co-locations were carried out in both indoor and outdoor environments. For outdoor co-location, the SPS30 and Panasonic PM 2.5 were carried by volunteers while walking, keeping both the sensors at the same elevation.

Finally, the third set of co-location experiments were performed before every field data collection. This was done to validate the sensors' performance before field measurements and ensure agreeability between both the sensors. The co-location experiments in this set involved both intra-sensor co-location and co-location relative to the reference instrument, GRIMM PAS 1.109. With respect to the reference instrument, the co-locations for both the sensors were performed in the ITS laboratory. For intra-sensor co-location, outdoor experiments were conducted at the data collection site, where volunteers carried both the sensors at the same height, and the corresponding outputs were compared.

The evaluation of intra-sensor co-location was performed by calculating the coefficient of variation (CV) for both the sensors' outputs. The coefficient of variation is usually used to determine 
the intra-sensor variability in measurements (Crilley et al., 2018). Eq. (3) was used for calculating the same.

$C V=\frac{\sigma}{\mu}$

Here, $\sigma$ is the standard deviation, and $\mu$ is the mean of the $\mathrm{PM}_{2.5}$ measurements from both the sensors. Acceptable values of CV for the two similar sensors, according to U.S. EPA, are up to 0.1 (Sousan et al., 2016b). For co-location experiments relative to the reference instrument, the Pearson correlation coefficient $(r)$ was calculated between the sensor's output and the reference instrument's output. Pearson correlation coefficient $(r)$ values $>0.97$ are acceptable between a test instrument and a reference instrument (Sousan et al., 2016b).

In addition to these accuracy metrics, statistical t-tests were also conducted to assess any statistical significance of the difference in intra-sensor, or sensor and reference instrument's output. One-minute average data from each of the sensors for the entire duration of the experiments were used for all the t-tests $(n>30)$. The R-Studio software was used for the t-test. These t-tests were conducted at $95 \%$ confidence with the null hypothesis as no difference in output and the alternative hypothesis as a difference in reading prevails. P-values greater than 0.05 for $t$-tests suggest null hypothesis acceptance, and less than 0.05 indicate alternative hypothesis acceptance. Overall, rigorous evaluations were performed for the low-cost sensors to ensure agreeability in their measurements.

\subsubsection{Data collection}

The field $\mathrm{PM}_{2.5}$ data collection was conducted on a pedestrian pathway located near the Sardar Patel Road, Chennai, India. The selected pathway is nearly $70 \mathrm{~m}$ in length. This particular pathway was selected for the experiments because it is situated near a busy urban road (Patra et al., 2021a; Sakhare and Vanajakshi, 2020) and is free from any interference from shops or buildings. The exposure of fine particulates to pedestrians on it can, therefore, be assumed to be primarily due to the adjacent traffic movements. Fig. 2 shows the study site used. For mobile $\mathrm{PM}_{2.5}$ measurements, a volunteer traversed the pathway with the SPS30 sensor mounted at the height of $150 \mathrm{~cm}$ and the Panasonic sensor tied at the height of $80 \mathrm{~cm}$ from the ground level. The position of both the sensors on the volunteer while collecting the $\mathrm{PM}_{2.5}$ data is shown in Fig. 3.

While the sensors were mounted, as shown in Fig. 3, the volunteer travelled back and forth thirty trips on the pathway (Fig. 2). To ensure repeatability, another round of data collection, in the same manner, was carried out another day.

The data regarding ambient $\mathrm{PM}_{2.5}$ were collected from a ground-level Central Pollution Control Board (CPCB) monitoring station (CPCB, 2020), located nearly $300 \mathrm{~m}$ away from the selected measurement site. Apart from this, the wind speed information at the field data collection site was downloaded from the NCEP/NCAR reanalysis dataset provided by the NOAA Physical Sciences Laboratory (PSL) (https://psl.noaa.gov/). This reanalysis is a state-of-the-art forecast method to assimilate meteorological information using data from 1948 to the present (Kalnay et al., 1996). The spatial coverage of the PSL dataset is $2.5^{\circ} \times 2.5^{\circ}$ on global grids. The measurement site is located in between $13.0068^{\circ} \mathrm{N}, 80.2000^{\circ} \mathrm{E}$ and $13.0068^{\circ} \mathrm{N}, 80.4500^{\circ} \mathrm{E}$. The corresponding surface-level wind speed data was downloaded for this grid. One thing to note here is that, due to lack of instrumentation, it was not possible to obtain the traffic volume data during both the data collection days. The data collection was performed on $29^{\text {th }}$ January 2020 at $10 \mathrm{AM}$ and $31^{\text {st }}$ January 2020 at 2 PM.

These were the methodologies used for the CALINE 4 simulation and $\mathrm{PM}_{2.5}$ mobile measurements. The results obtained are discussed in the next section.

\section{RESULTS AND DISCUSSION}

\subsection{CALINE 4 Simulation Results}

Fig. 4 shows the variations of $\mathrm{PM}_{2.5}$ for varying heights of the receptors for two sample model 


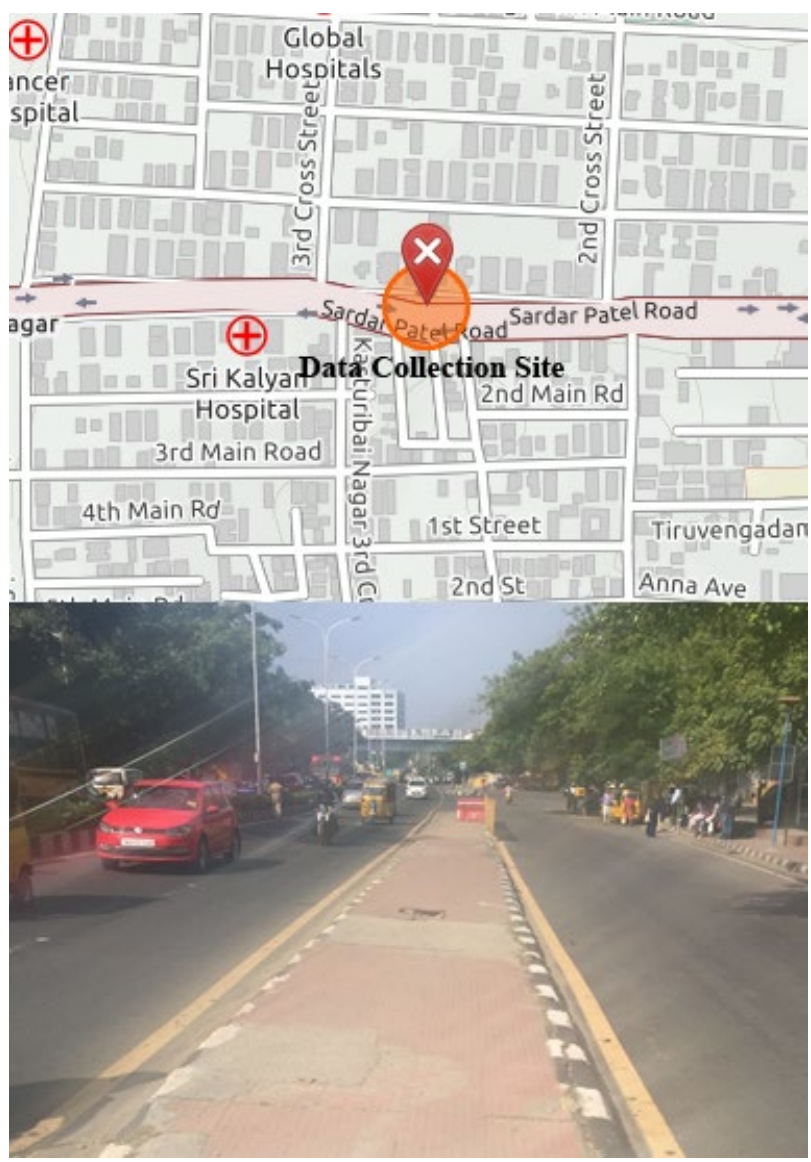

Fig. 2. Data collection site for mobile $\mathrm{PM}_{2.5}$ measurements.

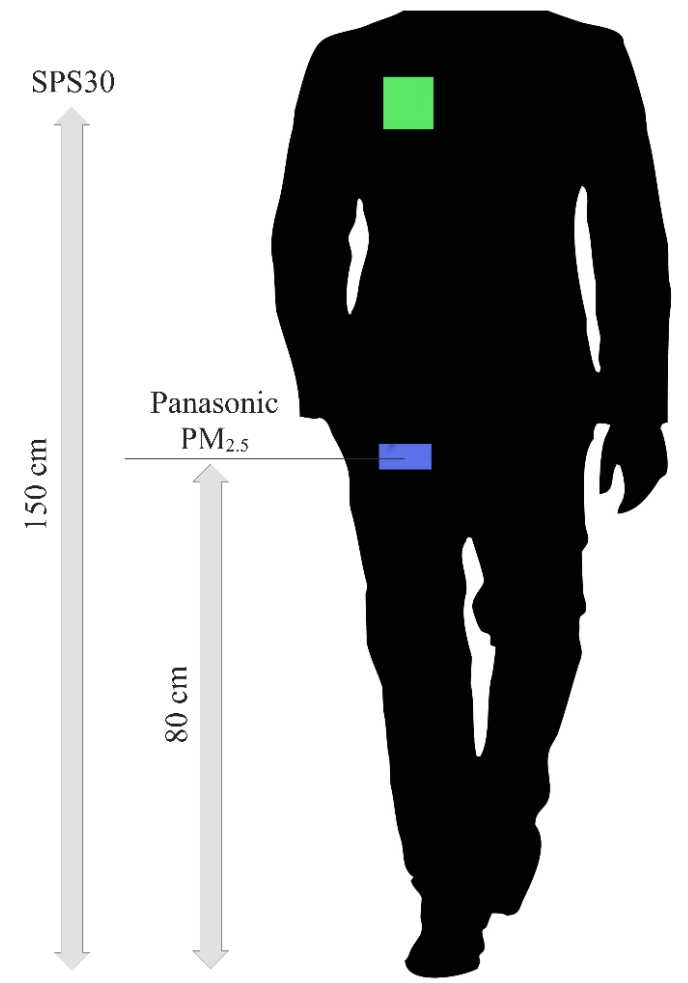

Fig. 3. Position of both the sensors (SPS30 and Panasonic $\mathrm{PM}_{2.5}$ ) as carried by the volunteer for mobile $\mathrm{PM}_{2.5}$ measurements on the pedestrian pathway. 

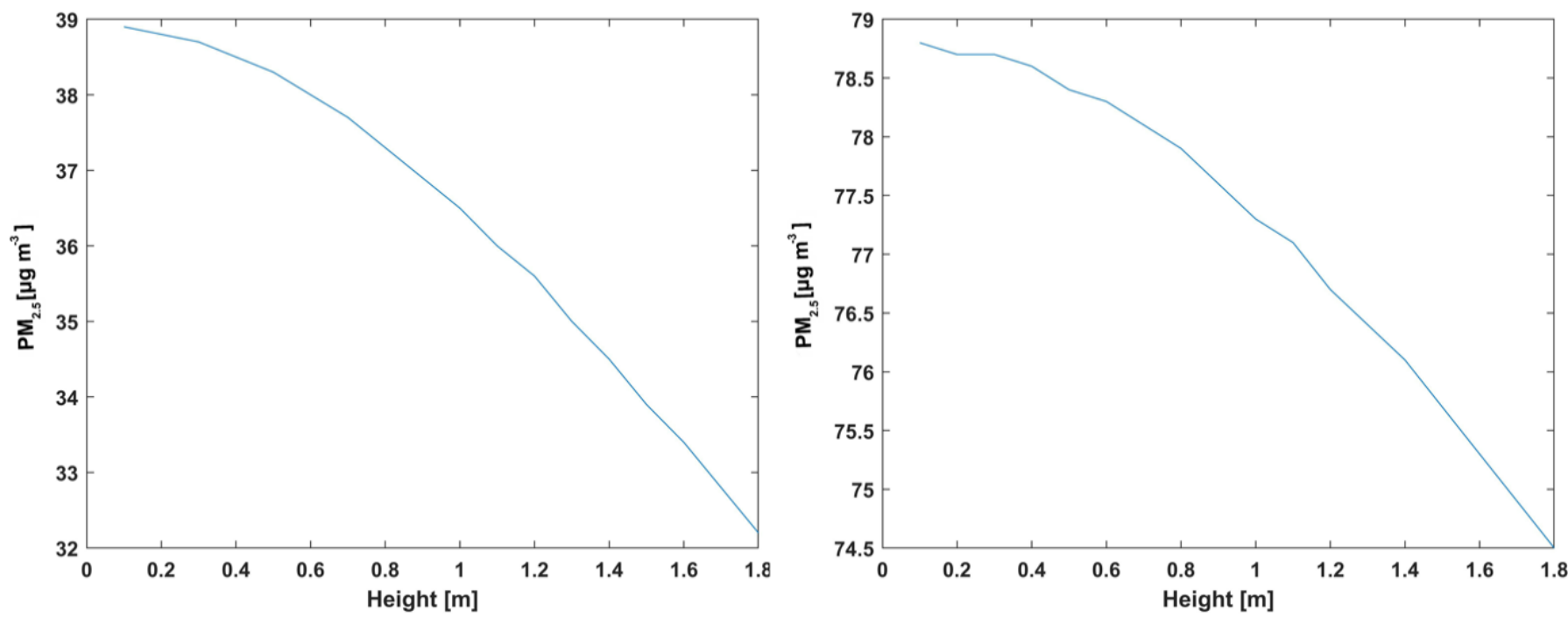

Fig. 4. Vertical variations in $\mathrm{PM}_{2.5}$ when ambient $\mathrm{PM}_{2.5}$ levels are low, wind speed is medium, traffic volume is high and traffic composition is Category I (left), and ambient PM $_{2.5}$ levels are high, wind speed is low, traffic volume is medium and traffic composition is Category III (right).

runs. For all the 135 scenarios, the vertical variations in the modelled $\mathrm{PM}_{2.5}$ concentrations are presented in Fig. S1(a) through S1(e) in the supplementary section. These figures are grouped based on the category of traffic composition.

Results indicate that the $\mathrm{PM}_{2.5}$ concentrations decreased as the height of the receptor increased for all the runs. The difference in $\mathrm{PM}_{2.5}$ concentration between receptors at $0.1 \mathrm{~m}$ and $1.8 \mathrm{~m}$ ranged from 1.3-8.3 $\mu \mathrm{g} \mathrm{m}^{-3}$. The lowest difference was observed when the wind speed was high with low traffic volume in category II vehicle composition, and the highest difference was reported for low wind speed and high traffic volume in category IV composition. Nevertheless, the results made it clear that pedestrians with shorter heights are exposed to a higher concentration of $\mathrm{PM}_{2.5}$ near busy roadways. Once this was established, $\mathrm{G}$ values were estimated for the $\mathrm{PM}_{2.5}$ concentration difference across height with varying traffic volume, traffic composition, wind speed, and ambient $\mathrm{PM}_{2.5}$ concentrations (as discussed in the previous section). Table 2 summarizes the effect of these variables on the $\mathrm{PM}_{2.5}$ concentration difference across height based on the absolute numerical value of $\mathrm{G}$ (which signifies the slope of $\mathrm{PM}_{2.5}$ concentration profile, assuming it to be linear).

From Table 2, the wind speed, traffic volume, and traffic composition emerged as the influencing variables determining vertical differences in pedestrian's exposure to $\mathrm{PM}_{2.5}$. Under traffic composition, car-dominated traffic with a higher proportion of HCVs increased the vertical difference in exposure. As the mode share of two-wheelers increased, the difference in exposure was found to reduce. For wind speed and traffic volume, lower wind speed and higher traffic volume increased the vertical difference in exposure. To further quantify their effect, additional

Table 2. Effect of different variables on the $\mathrm{PM}_{2.5}$ concentration difference at varying heights (absolute numerical value of $\mathrm{G}$ signifies the slope of $\mathrm{PM}_{2.5}$ concentration difference across the evaluated height (calculated using Eq. (2)).

\begin{tabular}{|c|c|}
\hline Variable & Effect \\
\hline $\begin{array}{l}\text { Ambient } \mathrm{PM}_{2.5} \\
\text { concentration }\end{array}$ & $\begin{array}{l}\text { /G / was independent of ambient } \mathrm{PM}_{2.5} \text { concentration. Thus, ambient } \mathrm{PM}_{2.5} \text { concentration did not } \\
\text { affect the vertical difference in } \mathrm{PM}_{2.5} \text { concentration across receptors. }\end{array}$ \\
\hline Wind Speed & $\begin{array}{l}\mid G / \text { decreased with increasing wind speeds. Therefore, with increase in wind speed, the vertical } \\
\text { difference in } \mathrm{PM}_{2.5} \text { concentration across receptors decreased. }\end{array}$ \\
\hline Traffic Volume & $\begin{array}{l}/ G / \text { increased with increasing traffic volume. Therefore, as the vehicle volume increased, the } \\
\text { vertical difference in } \mathrm{PM}_{2.5} \text { concentration across receptors increased. }\end{array}$ \\
\hline Traffic Composition & $\begin{array}{l}I G / \text { followed the following order for different traffic compositions: Category IV }>\text { Category I }> \\
\text { Category III }>\text { Category V }>\text { Category II. Therefore, for car dominated traffic with higher } \\
\text { proportions of HCVs increased the vertical difference in } \mathrm{PM}_{2.5} \text { concentrations for pedestrians. }\end{array}$ \\
\hline
\end{tabular}


CALINE 4 simulated runs were performed. In these runs, the value of the variable of interest was increased sequentially while keeping other variables constant. Subsequently, the $G$ was calculated for each changing value of the variable of interest and analyzed. It was observed that for every increase in vehicular volume by 100 vehicles $\mathrm{hr}^{-1}$, the $\mathrm{PM}_{2.5}$ exposure difference increased by $0.13 \mu \mathrm{g} \mathrm{m}^{-3} \mathrm{~m}^{-1}$ in the range of pedestrian's height (Fig. S2 in the supplementary section). For wind speed, calculations suggested that for every $1 \mathrm{~m} \mathrm{~s}^{-1}$ increase in wind speed, the $\mathrm{PM}_{2.5}$ exposure difference reduced by $0.095 \mu \mathrm{g} \mathrm{m}^{-3} \mathrm{~m}^{-1}$ in the range of pedestrian's height (Fig. S3 in the supplementary section).

The above results suggest that $\mathrm{PM}_{2.5}$ concentration exposure for short pedestrians is higher compared to tall pedestrians. Moreover, a region characterized by low wind speeds, or high traffic volume, or more HCVs in traffic, or a combination of any of these conditions would tend to increase this exposure difference. The results of the field study verifying the simulation results are discussed next.

\subsection{Field Measurement Results}

\subsubsection{Sensor co-location results}

The first set of co-location experiments was conducted to evaluate the performance of sensors used (SPS30 and Panasonic PM $_{2.5}$ ) relative to the reference instrument (GRIMM PAS 1.109). Results obtained for the indoor co-locations are shown in Figs. S4 and S5 in the supplementary section and the outdoor co-location in Fig. S6. From the figures, it can be observed that the performance of both the sensors relative to the state-of-the-art-reference instrument is comparable. To corroborate this, the Pearson correlation coefficient $(r)$ was calculated. For SPS30, the value of $r$ was 0.975 , and for Panasonic PM $_{2.5}$, the $r$ came to be 0.972 . These values met the U.S. EPA's requirements for performance comparison between a test and a reference instrument. In addition, the $p$-value for the t-test at $95 \%$ confidence for both the sensors' output was obtained as 0.78 for SPS30 and 0.74 for Panasonic PM 2.5. Therefore, statistically, also no significant difference was observed between the sensors' output and the reference instrument's output.

The second set of co-location experiments were performed where the sensors were co-located against each other. As discussed before, this was done for both indoor and outdoor environments. Figs. S7 and S8 present the results obtained. The performance comparison plots indicate that the sensors' output is comparable with one another under similar conditions. To quantify this, CV was calculated. The CV values for indoor co-location was 0.014 , and for outdoor co-location was 0.025 , which are well within limits prescribed by U.S. EPA (which is 0.1 ). Also, the p-value for the t-test at $95 \%$ confidence for both the sensors' output came to be 0.55 for indoor co-location and 0.48 for outdoor co-location. This confirms a statistically insignificant disparity in outputs from both the sensors with respect to each other under identical conditions.

Finally, the third set of co-location experiments were conducted before field data collection on both days. In these experiments, the sensors' outputs were compared relative to the reference instrument and with respect to each other when kept at the same height at the field measurement site. The results of these co-location experiments are summarized in Table S1. It can be seen that the CV values of intra-sensor comparison were within the prescribed limits of U.S. EPA during all the experiments. The t-tests also suggested insignificant differences in their outputs. When evaluated against the reference instrument, both the SPS30 and the Panasonic PM 2.5 sensors' outputs were deemed comparable. Furthermore, the CV and the p-values of the t-tests at the measurement site indicate that the outputs of $\mathrm{PM}_{2.5}$ from both the sensors, when held at the same height, did not differ significantly. Therefore, from all the co-location experiments conducted, it was confirmed that both the sensors used in the study performed identically at the same height from the ground level, and the $\mathrm{PM}_{2.5}$ outputs of the sensors were comparable to the values given by the reference instrument.

\subsubsection{Field data collection results}

The ambient meteorological data downloaded from the nearby monitoring station, ambient $\mathrm{PM}_{2.5}$ data and the PSL dataset during the hours of data collection are summarized in Table 3. Data averaging period from the source was chosen such that it included the time of the experiment.

The CALINE 4 simulation results suggested that wind speed, traffic volume, and traffic composition 
Table 3. Summary of ambient meteorological parameters and $\mathrm{PM}_{2.5}$ concentrations at the field data collection site during both the days of data collection.

\begin{tabular}{lllll}
\hline Day of Experiment & Data Source & Data Averaging Period & Parameter & Value \\
\hline Day 1 & CPCB & 10-11 AM & PM $_{2.5}$ & $63.87 \mu \mathrm{m} \mathrm{m}^{-3}$ \\
& & & Wind Speed & $3.63 \mathrm{~m} \mathrm{~s}^{-1}$ \\
& PSL & 6 AM-12 PM & Wind Speed & Max: $5.25 \mathrm{~m} \mathrm{~s}^{-1}$ \\
& & & & Min: $3.2 \mathrm{~m} \mathrm{~s}^{-1}$ \\
Day 2 & CPCB & 2-3 PM & PM 2.5 & $15.01 \mu \mathrm{m} \mathrm{m}^{-3}$ \\
& & & Wind Speed & $5.97 \mathrm{~m} \mathrm{~s}^{-1}$ \\
& PSL & 12-6 PM & Wind Speed & Max: $5.75 \mathrm{~m} \mathrm{~s}^{-1}$ \\
\end{tabular}

influenced the vertical differences in $\mathrm{PM}_{2.5}$ concentrations near roadways. As the same site was used for the data collection on both days, the traffic mode share is expected to remain more or less the same. For wind speed, Day 1 was marked with lower wind speed compared to that in Day 2 (Table 3). On Day 1, the data was collected during the morning office-time peak hour, while on Day 2, the data was collected during the afternoon off-peak period. Hence, Day 1 was characterized by higher traffic volume compared to Day 2. However, the numerical value of the vehicular volume is not available due to the lack of instrumentation at the site.

Fig. 5 compares the $\mathrm{PM}_{2.5}$ concentrations recorded at $80 \mathrm{~cm}$ and $150 \mathrm{~cm}$ while walking at the site during experiments for both the days (the time series of $\mathrm{PM}_{2.5}$ concentrations while walking at the site during the experiments for both the days is shown in Fig. 6). The $\mathrm{PM}_{2.5}$ concentration at $80 \mathrm{~cm}$ was observed to be consistently higher than the concentration recorded at $150 \mathrm{~cm}$ for both days. For the first day, the mean $\mathrm{PM}_{2.5}$ concentration at $80 \mathrm{~cm}$ was $56.68 \mu \mathrm{g} \mathrm{m}^{-3}$ (std dev: $6.02 \mu \mathrm{g} \mathrm{m}^{-3}$ ) and at $150 \mathrm{~cm}$ was $45.59 \mu \mathrm{g} \mathrm{m}^{-3}$ (std dev: $5.85 \mu \mathrm{g} \mathrm{m}^{-3}$ ), and on the second day, the mean $\mathrm{PM}_{2.5}$ concentration at $80 \mathrm{~cm}$ was $26.33 \mu \mathrm{g} \mathrm{m}^{-3}$ (std dev: $2.40 \mu \mathrm{g} \mathrm{m}^{-3}$ ) and at $150 \mathrm{~cm}$ was $21.24 \mu \mathrm{g} \mathrm{m}^{-3}$ (std dev: $1.92 \mu \mathrm{g} \mathrm{m}^{-3}$ ). The results were tested statistically using one-tailed paired t-tests with a null hypothesis as no difference in readings at $80 \mathrm{~cm}$ and $150 \mathrm{~cm}$, and an alternative hypothesis as $\mathrm{PM}_{2.5}$ levels at $80 \mathrm{~cm}$ is greater than that observed at $150 \mathrm{~cm}$. The $p$-value for the data collected on the first day was $2.12 \times 10^{-12}$ and was $1.88 \times 10^{-21}$ for the second day. Such lower $\mathrm{p}$-values strongly indicate rejecting the null hypothesis, accepting the alternative one at a confidence of $95 \%$. Therefore, statistically strong evidence exists that levels of $\mathrm{PM}_{2.5}$ observed at $80 \mathrm{~cm}$ height are higher than the levels observed at $150 \mathrm{~cm}$ on both days.

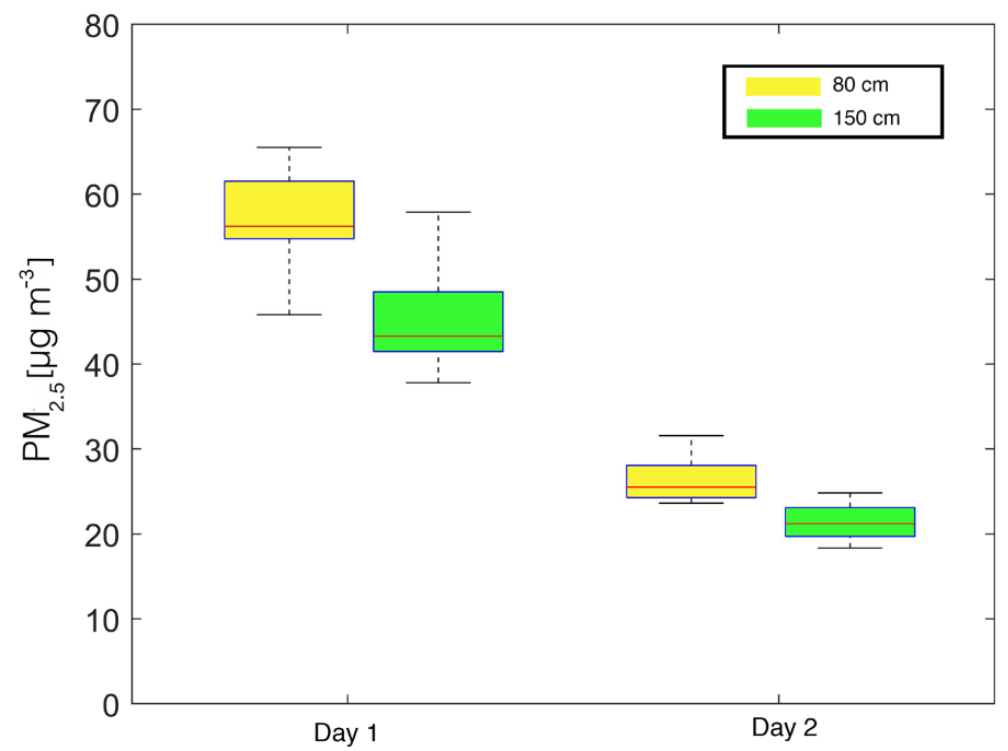

Fig. 5. Comparison of $\mathrm{PM}_{2.5}$ concentration recorded at $80 \mathrm{~cm}$ and $150 \mathrm{~cm}$ while walking at the site during experiments for both the days. 

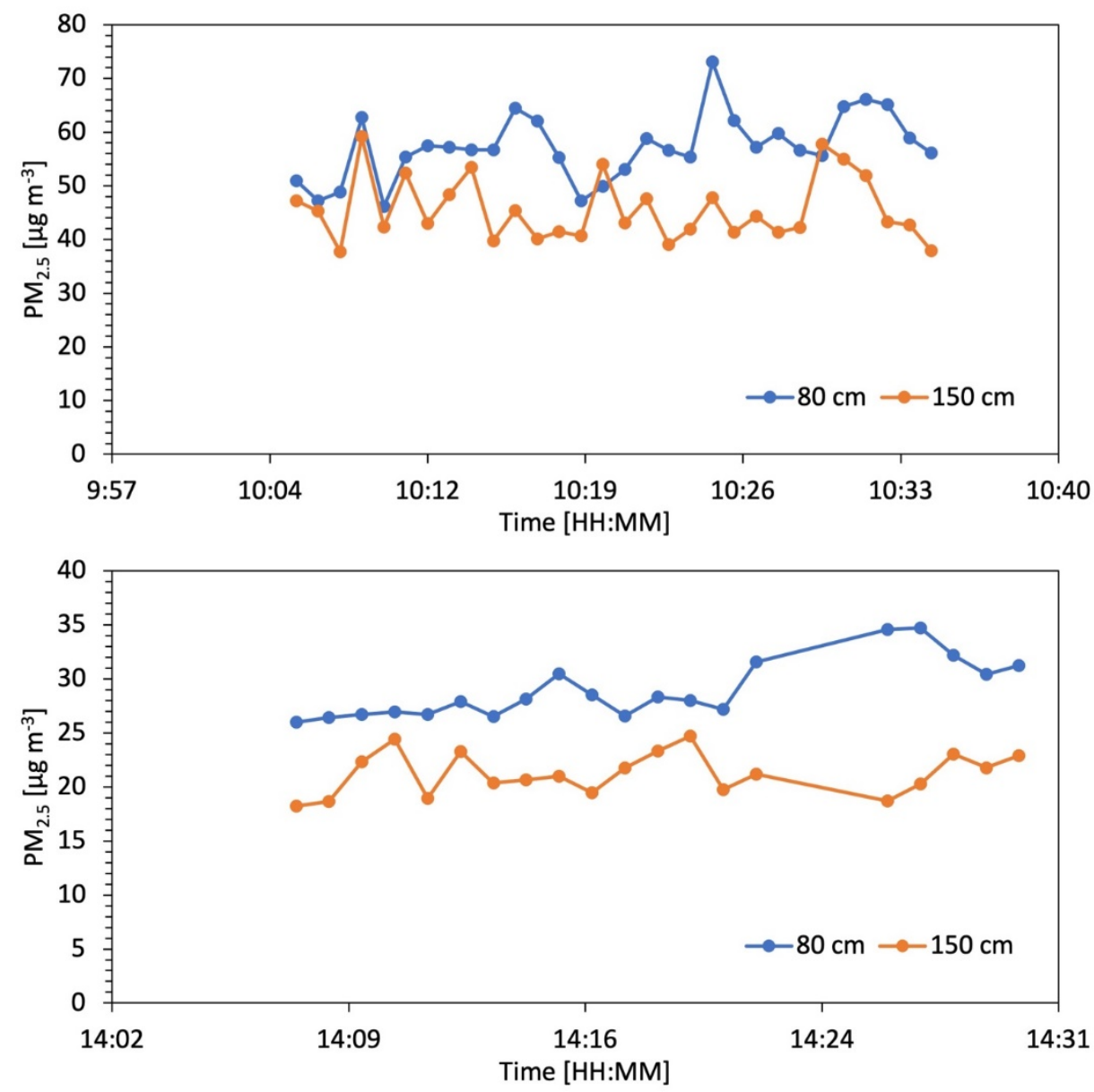

Fig. 6. Comparison of $\mathrm{PM}_{2.5}$ concentrations recorded at $80 \mathrm{~cm}$ and $150 \mathrm{~cm}$ while walking at the site during experiments: (top) during peak traffic hours; (bottom) during off peak hours.

In addition, it was observed that the difference in $\mathrm{PM}_{2.5}$ concentrations at $80 \mathrm{~cm}$ and $150 \mathrm{~cm}$ was higher on Day 1 compared to Day 2. As previously stated, Day 1 was marked with a higher traffic volume and lower wind speed. The results from CALINE 4 simulations suggested that such a combination enhances the $\mathrm{PM}_{2.5}$ difference across heights, which was also observed for mobile measurements.

Overall, the current study's results suggest that $\mathrm{PM}_{2.5}$ exposure levels are reduced with increasing heights of pedestrians. It was also observed that with increasing traffic volume, or decreasing wind speed, or increasing mode share of HCVs, the difference in exposure increased. CALINE 4 based results showed that for every 100 vehicles $\mathrm{hr}^{-1}$ increase in traffic volume, the $\mathrm{PM}_{2.5}$ exposure difference increased by $0.13 \mu \mathrm{g} \mathrm{m}^{-3} \mathrm{~m}^{-1}$ in the range of pedestrian's height. For wind speed, calculations suggested that for every $1 \mathrm{~m} \mathrm{~s}^{-1}$ increase in wind speed, the $\mathrm{PM}_{2.5}$ exposure difference was reduced by $0.095 \mu \mathrm{g} \mathrm{m}^{-3} \mathrm{~m}^{-1}$ in the range of pedestrian's height.

\section{CONCLUSIONS}

The current study examined how $\mathrm{PM}_{2.5}$ concentrations change with varying heights of pedestrians near roadways. CALINE 4 was used to simulate a variety of different scenarios involving vehicle volume, traffic composition, wind speed, and ambient $\mathrm{PM}_{2.5}$ concentrations to explore the gradient in $\mathrm{PM}_{2.5}$ concentrations with height. On-site mobile measurements supplemented the CALINE 4 observations. These observations showed that the $\mathrm{PM}_{2.5}$ concentration decreased with increasing heights of pedestrians. Furthermore, it was found that the difference in exposure across the heights of pedestrians is influenced by traffic volume, wind speed, and traffic composition. 
However, the on-site $\mathrm{PM}_{2.5}$ measurements were performed using low-cost particle sensors. Although low-cost sensors have recently been increasingly popular for personal evaluation and urban monitoring studies, their accuracy has always been a concern. Hence, the present study evaluated the performance of these sensors against a laboratory-grade optical particle counter (GRIMM PAS 1.109) in both indoor and outdoor conditions. The low-cost sensors were found to agree well with each other and GRIMM OPC in both indoor and outdoor conditions. Despite this, due to limited field data, the present study did not comment on the quantitative differences in $\mathrm{PM}_{2.5}$ values obtained from the on-site measurement experiments but was restricted to relative variations. The study primarily aims to understand the effect of pedestrians' height on their exposure level near the roadway at varying conditions of vehicle volume, traffic composition, wind speed, and ambient $\mathrm{PM}_{2.5}$ concentrations, and flags height of pedestrians as an influential variable under changing conditions of vehicle volume, traffic composition, and wind speed. Mobile measurements were used to verify the simulated CALINE 4 observation of decreasing $\mathrm{PM}_{2.5}$ concentrations for a taller pedestrian relative to a shorter pedestrian. However, one of the study's shortcomings is that the CALINE 4 do not account for the non-exhaust fraction of traffic emissions. According to Conte et al. (2019), non-exhaust traffic emissions account for a sizable portion of total traffic-related emissions, particularly in the coarse mode. Being coarse mode particles, they would thus tend to settle down (Patra et al., 2021b). As a result, it is likely that the non-exhaust fraction of traffic emissions will contribute to further increasing particle concentrations at low levels. This could be one of the reasons for the disparity between simulation and field observations (Fig. 6 and Fig. S1(a-e)). Therefore, to gain a more quantitative understanding of exposure differences, future research is needed to confirm the study's findings by conducting controlled experiments over a longer period using laboratory-grade PM instruments to quantify the differences in $\mathrm{PM}_{2.5}$ concentrations with varying pedestrian heights.

\section{ACKNOWLEDGMENTS}

The authors would like to thank Dr. Sachin S. Gunthe, EWRE division, IIT Madras and Dr. Gitakrishnan Ramadurai, Transportation division, IIT Madras for providing required instruments to carry out this study. The first author would also like to thank Dr. Brandon E. Boor, Purdue University, for introducing him to low-cost PM sensors.

\section{DISCLAIMER}

The authors declare that they do not have any conflicts of interest.

\section{SUPPLEMENTARY MATERIAL}

Supplementary material for this article can be found in the online version at https://doi. org/10.4209/aaqr.210104

\section{REFERENCES}

Agharkar, A. (2017). Model validation and comparative performance evaluation of MOVES/CALINE4 and generalized additive models for near-road black carbon prediction. Master's thesis, University of Cincinnati, USA. http://rave.ohiolink.edu/etdc/view?acc_num=ucin1490350586 489513

Amouei Torkmahalleh, M., Hopke, P.K., Broomandi, P., Naseri, M., Abdrakhmanov, T., Ishanov, A., Kim, J., Shah, D., Kumar, P. (2020). Exposure to particulate matter and gaseous pollutants during cab commuting in Nur-Sultan city of Kazakhstan. Atmos. Pollut. Res. 11, 880-885. https://doi.org/10.1016/j.apr.2020.01.016

Atkinson, R.W., Analitis, A., Samoli, E., Fuller, G.W., Green, D.C., Mudway, I.S., Anderson, H.R., Kelly, F.J. (2016). Short-term exposure to traffic-related air pollution and daily mortality in London, UK. J. Exposure Sci. Environ. Epidemiol. 26, 125-132. https://doi.org/10.1038/jes.2015.65 
Automotive Research Association of India (ARAI) (2007). Emission Factor development for Indian Vehicles. Automotive Research Association of India, India.

Batterman, S.A., Zhang, K., Kononowech, R. (2010). Prediction and analysis of near-road concentrations using a reduced-form emission/dispersion model. Environ. Health 9, 29. https://doi.org/10.1186/1476-069X-9-29

Benson, P.E. (1984). Caline 4-A Dispersion Model for Predictiong Air Pollutant Concentrations Near Roadways. Final Report prepared by the Caltrans Division of New Technology and Research (Report No. FHWA/CA/TL-84/15).

Benson, P.E. (1988). Development and verification of california line source dispersion model. Transp. Res. Rec. 1176, 69-76. https://onlinepubs.trb.org/Onlinepubs/trr/1988/1176/1176010.pdf

Bi, J., Wildani, A., Chang, H.H., Liu, Y. (2020). Incorporating low-cost sensor measurements into high-resolution $\mathrm{PM}_{2.5}$ modeling at a large spatial scale. Environ. Sci. Technol. 54, 2152-2162. https://doi.org/10.1021/acs.est.9b06046

Boarnet, M.G., Houston, D., Edwards, R., Princevac, M., Ferguson, G., Pan, H., Bartolome, C. (2011). Fine particulate concentrations on sidewalks in five Southern California cities. Atmos. Environ. 45, 4025-4033. https://doi.org/10.1016/j.atmosenv.2011.04.047

Carvalho, R.B., Fernanda, M., Carneiro, H., Barbosa, F., Lemos Batista, B., Simonetti, J., Luis Amantéa, S., Cláudia, Rhoden, R. (2018). The impact of occupational exposure to traffic-related air pollution among professional motorcyclists from Porto Alegre, Brazil, and its association with genetic and oxidative damage. Environ. Sci. Pollut. Res. 25, 18620-18631. https://doi.org/ 10.1007/s11356-018-2007-1

Central Pollution Control Board (CPCB) (2020). CCR Webap. https://app.cpcbccr.com/ccr/\# /caaqm-dashboard-all/caaqm-landing/data (accessed 7 May 2020).

Chen, H., Bai, S., Eisinger, D., Niemeier, D., Claggett, M. (2009). Predicting near-road PM 2.5 concentrations: Comparative assessment of CALINE4, CAL3QHC, and AERMOD. Transp. Res. Rec. 2123, 26-37. https://doi.org/10.3141/2123-04

Chen, S., Cui, K., Yu, T.Y., Chao, H.R., Hsu, Y.C., Lu, I.C., Arcega, R.D., Tsai, M.H., Lin, S.L., Chao, W.C., Chen, C., Yu, K.L.J. (2019). A big data analysis of $\mathrm{PM}_{2.5}$ and $\mathrm{PM}_{10}$ from low cost air quality sensors near traffic areas. Aerosol Air Qual. Res. 19, 1721-1733. https://doi.org/10.4209/aaqr. 2019.06.0328

Chen, Y., Wild, O., Conibear, L., Ran, L., He, J., Wang, L., Wang, Y. (2020). Local characteristics of and exposure to fine particulate matter $\left(\mathrm{PM}_{2.5}\right)$ in four indian megacities. Atmos. Environ.: X 5, 100052. https://doi.org/10.1016/j.aeaoa.2019.100052

Conte, M., Donateo, A., Contini, D. (2018). Characterisation of particle size distributions and corresponding size-segregated turbulent fluxes simultaneously with $\mathrm{CO}_{2}$ exchange in an urban area. Sci. Total Environ. 622-623, 1067-1078. https://doi.org/10.1016/j.scitotenv.2017.12.040

Conte, M., Contini, D. (2019). Size-resolved particle emission factors of vehicular traffic derived from urban eddy covariance measurements. Environ. Pollut. 251, 830-838. https://doi.org/10. 1016/j.envpol.2019.05.029

Crilley, L.R., Shaw, M., Pound, R., Kramer, L.J., Price, R., Young, S., Lewis, A.C., Pope, F.D. (2018). Evaluation of a low-cost optical particle counter (Alphasense OPC-N2) for ambient air monitoring. Atmos. Meas. Tech. 11, 709-720. https://doi.org/10.5194/amt-11-709-2018

Datta, A., Saha, A., Zamora, M.L., Buehler, C., Hao, L., Xiong, F., Gentner, D.R., Koehler, K. (2020). Statistical field calibration of a low-cost $\mathrm{PM}_{2.5}$ monitoring network in Baltimore. Atmos. Environ. 242, 117761. https://doi.org/10.1016/j.atmosenv.2020.117761

Dhyani, R., Sharma, N. (2017). Sensitivity analysis of CALINE4 model under mix traffic conditions. Aerosol Air Qual. Res. 17, 314-329. https://doi.org/10.4209/aaqr.2016.01.0012

Dhyani, R., Singh, A., Sharma, N., Gulia, S. (2013). Performance evaluation of CALINE 4 model in a hilly terrain-a case study of highway corridors in Himachal Pradesh (India). Int. J. Environ. Pollut. 52, 244-262. https://doi.org/10.1504/IJEP.2013.058455

Dinoi, A., Donateo, A., Belosi, F., Conte, M., Contini, D. (2017). Comparison of atmospheric particle concentration measurements using different optical detectors: Potentiality and limits for air quality applications. Measurement 106, 274-282. https://doi.org/10.1016/j.measurem ent.2016.02.019

U.S. Environmental Protection Agency (U.S. EPA) (1997). 40 CFR Parts 50- Reference Method for 
the Determination of Fine Particulate Matter as $\mathrm{PM}_{2.5}$ in the Atmosphere (Appendix L). https://www.law.cornell.edu/cfr/text/40/appendix-L_to_part_50 (accessed 1 July 2020).

Feenstra, B., Papapostolou, V., Hasheminassab, S., Zhang, H., Boghossian, B., Der, Cocker, D., Polidori, A. (2019). Performance evaluation of twelve low-cost $\mathrm{PM}_{2.5}$ sensors at an ambient air monitoring site. Atmos. Environ. 216, 116946. https://doi.org/10.1016/j.atmosenv.2019.116946

Forehead, H., Barthelemy, J., Arshad, B., Verstaevel, N., Price, O., Perez, P. (2020). Traffic exhaust to wildfires: $\mathrm{PM}_{2.5}$ measurements with fixed and portable, low-cost LoRaWAN-connected sensors. PLoS One 15, e0231778. https://doi.org/10.1371/journal.pone.0231778

Fung, D.C., Zhang, Q., Hinds, W.C., Zhu, Y. (2013). Particle concentration on freeways: Affecting factors and a simple model development. Aerosol Air Qual. Res. 13, 1693-1701. https://doi.org/10.4209/aaqr.2013.04.0110

Gao, M., Cao, J., Seto, E. (2015). A distributed network of low-cost continuous reading sensors to measure spatiotemporal variations of $\mathrm{PM}_{2.5}$ in Xi'an, China. Environ. Pollut. 199, 56-65. https://doi.org/10.1016/j.envpol.2015.01.013

Goel, A., Kumar, P. (2015). Characterisation of nanoparticle emissions and exposure at traffic intersections through fast-response mobile and sequential measurements. Atmos. Environ. 107, 374-390. https://doi.org/10.1016/j.atmosenv.2015.02.002

Goel, A., Kumar, P. (2016). Vertical and horizontal variability in airborne nanoparticles and their exposure around signalised traffic intersections. Environ. Pollut. 214, 54-69. https://doi.org/1 0.1016/j.envpol.2016.03.033

Goel, R., Gani, S., Guttikunda, S.K., Wilson, D., Tiwari, G. (2015). On-road PM2.5 pollution exposure in multiple transport microenvironments in Delhi. Atmos. Environ. 123, 129-138. https://doi.org/10.1016/j.atmosenv.2015.10.037

Goud, S.B., Savadatti, S., Prathibha, D. (2015). Application of Caline 4 model to predict $\mathrm{PM}_{2.5}$ concentration at central silk board traffic intersection of Bangalore city. Int. J. Civ. Eng. Technol. 6, 191-220.

Greaves, S., Issarayangyun, T., Liu, Q. (2008.) Exploring variability in pedestrian exposure to fine particulates $\left(\mathrm{PM}_{2.5}\right)$ along a busy road. Atmos. Environ. 42, 1665-1676. https://doi.org/10.101 6/j.atmosenv.2007.11.043

GRIMM (2010). GRIMM AEROSOL, Portable Laser Aerosol Spectrometer.

Guilbert, A., De Cremer, K., Heene, B., Demoury, C., Aerts, R., Declerck, P., Brasseur, O., Van Nieuwenhuyse, A. (2019). Personal exposure to traffic-related air pollutants and relationships with respiratory symptoms and oxidative stress: A pilot cross-sectional study among urban green space workers. Sci. Total Environ. 649, 620-628. https://doi.org/10.1016/j.scitotenv.20 18.08.338

Hassanpour Matikolaei, S.A.H., Jamshidi, H., Samimi, A. (2019). Characterizing the effect of traffic density on ambient $\mathrm{CO}, \mathrm{NO}_{2}$, and $\mathrm{PM}_{2.5}$ in Tehran, Iran: An hourly land-use regression model. Transp. Lett. 11, 436-446. https://doi.org/10.1080/19427867.2017.1385201

Hinds, W.C. (1999). Aerosol technology: Properties, behavior, and measurement of airborne particles. John Wiley \& Sons.

Holmes, N.S., Morawska, L., Mengersen, K., Jayaratne, E.R. (2005). Spatial distribution of submicrometre particles and $\mathrm{CO}$ in an urban microscale environment. Atmos. Environ. 39, 3977-3988. https://doi.org/10.1016/j.atmosenv.2005.03.049

Kalnay, E., Kanamitsu, M., Kistler, R., Collins, W., Deaven, D., Gandin, L., Iredell, M., Saha, S., White, G., Woollen, J., Zhu, Y., Chelliah, M., Ebisuzaki, W., Higgins, W., Janowiak, J., Mo, K.C., Ropelewski, C., Wang, J., Leetmaa, A., Reynolds, R., Jenne, R., Joseph, D. (1996). The NCEP/NCAR 40-Year Reanalysis Project. Bull. Am. Meteorol. Soc. 77, 437-472. https://doi.org/10.1175/152 0-0477(1996)077<0437:TNYRP>2.0.CO;2

Kanok, B., Waheed, U. (2006). Simplified methodology to estimate emissions from mobile sources for ambient air quality assessment. J. Transp. Eng. 132, 817-828. https://doi.org/10.10 61/(ASCE)0733-947X(2006)132:10(817)

Kaur, S., Nieuwenhuijsen, M.J., Colvile, R.N. (2007). Fine particulate matter and carbon monoxide exposure concentrations in urban street transport microenvironments. Atmos. Environ. 41, 4781-4810. https://doi.org/10.1016/j.atmosenv.2007.02.002

Krause, A., Zhao, J., Birmili, W. (2019). Low-cost sensors and indoor air quality: A test study in three residential homes in Berlin, Germany/Kostengünstige Sensoren und Innenraumluftqualität: 
Eine Testuntersuchung in drei Privathaushalten in Berlin. Gefahrstoffe 79, 87-92. https://doi.org/10.37544/0949-8036-2019-03-49

Kumar, P., Goel, A. (2016). Concentration dynamics of coarse and fine particulate matter at and around signalised traffic intersections. Environ. Sci. Processes Impacts 18, 1220-1235. https://doi.org/10.1039/C6EM00215C

Laverty, A.A., Mindell, J.S., Webb, E.A., Millett, C. (2013). Active travel to work and cardiovascular risk factors in the United Kingdom. Am. J. Prev. Med. 45, 282-288. https://doi.org/10.1016/j.a mepre.2013.04.012

Lim, C.C., Kim, H., Vilcassim, M.J.R., Thurston, G.D., Gordon, T., Chen, L.C., Lee, K., Heimbinder, M., Kim, S.Y. (2019). Mapping urban air quality using mobile sampling with low-cost sensors and machine learning in Seoul, South Korea. Environ. Int. 131, 105022. https://doi.org/10.101 6/j.envint.2019.105022

Luo, J., Boriboonsomsin, K., Barth, M. (2018). Reducing pedestrians ' inhalation of tra ffi c-related air pollution through route choices: Case study in California suburb. J. Transp. Health 10, 111123. https://doi.org/10.1016/j.jth.2018.06.008

Magi, B.I., Cupini, C., Francis, J., Green, M., Hauser, C. (2020). Evaluation of $\mathrm{PM}_{2.5}$ measured in an urban setting using a low-cost optical particle counter and a Federal Equivalent Method Beta Attenuation Monitor. Aerosol Sci. Technol. 54, 147-159. https://doi.org/10.1080/02786826.2 019.1619915

Majumdar, B.K., Dutta, A., Chakrabarty, S., Ray, S. (2008). Correction factors of CALINE 4: A study of automobile pollution in Kolkata. Indian J. Air Pollut. Control 8, 1-7.

Majumdar, B.K., Dutta, A., Chakrabarty, S., Ray, S. (2010). Assessment of vehicular pollution in Kolkata, India, using CALINE 4 model. Environ. Monit. Assess. 170, 33-43. https://doi.org/10.1 007/s10661-009-1212-2

Matz, C.J., Egyed, M., Hocking, R., Seenundun, S., Charman, N., Edmonds, N. (2019). Human health effects of traffic-related air pollution (TRAP): A scoping review protocol. Syst. Rev. 8, 223. https://doi.org/10.1186/s13643-019-1106-5

Merico, E., Dinoi, A., Contini, D. (2019). Development of an integrated modelling-measurement system for near-real-time estimates of harbour activity impact to atmospheric pollution in coastal cities. Transp. Res. Part D Transp. Environ. 73, 108-119. https://doi.org/10.1016/j.trd.2 019.06.009

Molnár, P., Janhäll, S., Hallquist, M. (2002). Roadside measurements of fine and ultrafine particles at a major road north of Gothenburg. Atmos. Environ. 36, 4115-4123. https://doi.org/10.1016/ S1352-2310(02)00183-8

Moreno-Rangel, A., Sharpe, T., Musau, F., McGill, G. (2018). Field evaluation of a low-cost indoor air quality monitor to quantify exposure to pollutants in residential environments. J. Sensors Sens. Syst. 7, 373-388. https://doi.org/10.5194/jsss-7-373-2018

Nakayama, T., Matsumi, Y., Kawahito, K., Watabe, Y. (2018). Development and evaluation of a palm-sized optical PM 2.5 sensor. Aerosol Sci. Technol. 52, 2-12. https://doi.org/10.1080/0278 6826.2017.1375078

Nawahda, A., Yamashita, K., Ohara, T., Kurokawa, J., Yamaji, K. (2012). Evaluation of premature mortality caused by exposure to $\mathrm{PM}_{2.5}$ and ozone in east Asia: 2000, 2005, 2020. Water Air Soil Pollut. 223, 3445-3459. https://doi.org/10.1007/s11270-012-1123-7

Omidvarborna, H., Kumar, P., Hayward, J., Gupta, M., Nascimento, E.G. (2021). Low-cost air quality sensing towards smart homes. Atmosphere 12, 453. https://doi.org/10.3390/atmos12 040453

Patra, S.S., Chilukuri, B.R., Vanajakshi, L. (2021a). Analysis of road traffic pattern changes due to activity restrictions during COVID-19 pandemic in Chennai. Transp. Lett. 13, 473-481. https://doi.org/10.1080/19427867.2021.1899580

Patra, S.S., Nath, J., Panda, S., Das, T., Ramasamy, B. (2021b). Evaluating the filtration efficiency of commercial facemasks' materials against respiratory aerosol droplets. J. Air Waste Manage. Assoc. https://doi.org/10.1080/10962247.2021.1948459

Patra, S.S., Ramsisaria, R., Du, R., Wu, T., Boor, B.E. (2021c). A machine learning field calibration method for improving the performance of low-cost particle sensors. Build. Environ. 190, 107457. https://doi.org/10.1016/j.buildenv.2020.107457

Prakash, B.M., Mahadevaswamy, M., Mahesh, S., Vishala, N. (2016). Prediction of Air Pollutants 
Dispersion Emitted from Point and Line Sources along the Highway Passing Through Industrial Area of Mysuru-AERMOD and CALINE4 Models. Int. J. Innovative Res. Sci. Eng. Technol. 5, $14497-14508$.

Qiu, Z., Li, X. (2015). At-grade intersection configuration influences on pedestrian exposure to $\mathrm{PM}_{2.5}$. Clean Technol. Environ. Policy 17, 2323-2335. https://doi.org/10.1007/s10098-0150975-0

Qiu, Z., Peng, X. (2015). Investigating the impact of urban grade-separation on pedestrian $\mathrm{PM}_{2.5}$ exposure. Clean Technol. Environ. Policy 17, 1917-1927. https://doi.org/10.1007/s10098-0150909-x

Quiros, D.C., Lee, E.S., Wang, R., Zhu, Y. (2013). Ultrafine particle exposures while walking, cycling, and driving along an urban residential roadway. Atmos. Environ. 73, 185-194. https://doi.org/10.1016/j.atmosenv.2013.03.027

Sakhare, R., Vanajakshi, L. (2020). Reliable corridor level travel time estimation using probe vehicle data. Transp. Lett. 12, 570-579. https://doi.org/10.1080/19427867.2019.1671041

Salvacao, N., Guedes Soares, C. (2015). Offshore wind energy assessment for the Iberian coast with a regional atmospheric model, in: Renewable Energies Offshore. Taylor \& Francis Group, London, pp. 219-228. https://doi.org/10.1201/b18973-33

Sampathkumar, V., Rajkumar, S.S. (2018). Traffic management at Madhya Kailash intersection along Rajiv Gandhi road in Chennai. Int. J. Eng. Technol. 7, 175. https://doi.org/10.14419/ijet.v 7i2.25.20501

Schneider, I.L., Teixeira, E.C., Silva, L.F.O., Wiegand, F. (2015). Atmospheric particle number concentration and size distribution in a traffic-impacted area. Atmos. Pollut. Res. 6, 877-885. https://doi.org/10.5094/APR.2015.097

Sensiron (2018). Particulate Matter Sensor SPS30. https://www.sensirion.com/en/environ mental-sensors/particulate-matter-sensors-pm25/ (accessed 1 July 2020).

SM, S.N., Reddy Yasa, P., MV, N., Khadirnaikar, S., Rani, P. (2019). Mobile monitoring of air pollution using low cost sensors to visualize spatio-temporal variation of pollutants at urban hotspots. Sustain. Cities Soc. 44, 520-535. https://doi.org/10.1016/j.scs.2018.10.006

Sousan, S., Koehler, K., Hallett, L., Peters, T.M. (2016a). Evaluation of the Alphasense optical particle counter (OPC-N2) and the Grimm portable aerosol spectrometer (PAS-1.108). Aerosol Sci. Technol. 50, 1352-1365. https://doi.org/10.1080/02786826.2016.1232859

Sousan, S., Koehler, K., Thomas, G., Park, J.H., Hillman, M., Halterman, A., Peters, T.M. (2016b). Inter-comparison of low-cost sensors for measuring the mass concentration of occupational aerosols. Aerosol Sci. Technol. 50, 462-473. https://doi.org/10.1080/02786826.2016.1162901

Tan, S.H., Roth, M., Velasco, E. (2017). Particle exposure and inhaled dose during commuting in Singapore. Atmos. Environ. 170, 245-258. https://doi.org/10.1016/j.atmosenv.2017.09.056

UnravelTEC (2019). GitHub - UnravelTEC/Raspi-Driver-SPS30: Software to read out Sensirion SPS30 PM sensor values over I2C on Raspberry Pi. https://github.com/UnravelTEC/RaspiDriver-SPS30 (accessed 1 July 2020).

Wang, H., Brimblecombe, P., Ngan, K. (2020). Particulate matter inside and around elevated walkways. Sci. Total Environ. 699, 134256. https://doi.org/10.1016/j.scitotenv.2019.134256

Wang, Z., Qiu, Z., Nie, D., He, R., Liu, W. (2021). Spatial distribution of the size-fractional PNC and Pedestrian exposure to PM at an urban signalized intersection. Build. Environ. 204, 108127. https://doi.org/10.1016/j.buildenv.2021.108127

World Health Organization (WHO) (2021). WHO I Ambient air pollution. https://www.wh o.int/airpollution/ambient/en/ (accessed 17 May 2020).

Zikova, N., Masiol, M., Chalupa, D.C., Rich, D.Q., Ferro, A.R., Hopke, P.K. (2017). Estimating hourly concentrations of $\mathrm{PM}_{2.5}$ across a metropolitan area using low-cost particle monitors. Sensors 17, 1922. https://doi.org/10.3390/s17081922 